\title{
EFEITOS DA GOVERNANÇA CORPORATIVA NA DISTRIBUIÇÃO DE DIVIDENDOS: UM ESTUDO EM EMPRESAS BRASILEIRAS
}

\author{
Daniel Henrique de Oliveira Souza ${ }^{1}$ \\ Fernanda Maciel Peixoto ${ }^{2}$ \\ Murilo Alves dos Santos ${ }^{3}$
}

Resumo: Esta pesquisa analisou a relação que a governança corporativa tem na distribuição de dividendos de empresas brasileiras de capital aberto não financeiras. Para tanto foram coletados e analisados dados de companhias brasileiras não financeiras listadas na BM\&F Bovespa, no período de 2002 a 2013. Para a análise, utilizou-se de regressão com dados em painel Pooled-OLS. A hipótese levantada parte das teorias de agência e do pássaro na mão e sugere-se que haja relação positiva entre a qualidade da governança corporativa das empresas (GC), classificada pela BM\&F Bovespa, e o montante de dividendos que as empresas distribuem aos seus acionistas. Os resultados encontrados mostraram que empresas com melhores práticas de governança corporativa pagam dividendos maiores do que aquelas com práticas de governança incipientes, que períodos de crise não influenciaram na forma de distribuição de dividendos e que alguns setores apresentaram significância estatística positiva na distribuição de dividendos. Para trabalhos futuros, sugere-se a análise individual da remuneração aos acionistas via dividendos ou por meio de juros sobre capital próprio, bem como análise dos quatro níveis de GC em separado, o uso de outras proxies para governança e o uso de métodos econométricos distintos para avaliar as variáveis de interesse.

Palavras-chave: Governança corporativa. Dividendos. Crise.

\footnotetext{
'E-mail: dhenrique.souza@gmail.com - Faculdade de Marketing e Negócios - Uniessa

${ }^{2}$ E-mail: fmacielpeixoto@gmail.com - Universidade Federal de Uberlândia

${ }^{3}$ E-mail: mualvesan@yahoo.com.br - Universidade Federal de Uberlândia

- DOI: http://dx.doi.org/10.14392/asaa.2016090104

- Artigo recebido em 24/10/2014. Revisões requeridas em: 01/10/2015. Aprovado em 15/04/2016
} 


\title{
EFFECTS OF GOVERNANCE GIVES CORPORATE IN THE DIVIDENDS DISTRIBUITION : A STUDY IN THE BRAZILIAN BUSINESS
}

\begin{abstract}
This research examined the relationship between corporate governance and the distribution of dividends of Brazilian public companies non-financial capital. For both were collected and analyzed data from Brazilian non-financial companies listed on the BM\&F Bovespa, from 2002 to 2013. For the analysis, we used data regression in Pooled-OLS panel. The hypothesis for the research comes from the theories of agency and bird in the hand and it is suggested that there is a positive relationship between the quality of corporate governance of companies (GC), classified by BM\&F Bovespa, and the amount of dividends that companies distribute to their shareholders. The results showed that companies with better corporate governance practices pay higher dividends than those with incipient governance practices, that the periods of crisis did not influence the form of the payment of dividends and that some sectors showed positive statistical significance in the distribution of dividends. For future work, we suggest the specific analysis of the dividends payment via interest on capital as well as analysis of the four levels of GC separately, using other proxies for GC and the use of different econometric methods to evaluate the variables of interest.
\end{abstract}

Keywords: Corporative governance. Dividends. Crisis. 


\section{INTRODUÇÃO}

A quantidade de empresaslistadas nos níveis diferenciados de Governança Corporativa da BM\&FBovespa apresentou uma evolução de 313\% entre os anos de 2004 e 2013, passando de 46 empresas listadas em 2004 para 190 em 2013 (BM\&FBovespa, 2013). Essa evolução, aliada à estabilidade da economia, proporcionou um grande crescimento de investidores no mercado (GAMA, et al, 2013), contribuindo para a maior necessidade de estudos realizados sobre o mercado de capitais brasileiro, a fim de compreender suas características e seu funcionamento.

Na evolução do mercado de capitais, os mecanismos de Governança Corporativa (GC) são relevantes (Peixoto, Buccini, 2014). Segundo La Porta, et al. (2000), o conjunto destes mecanismos existe para proteger investidores externos à organização, com o objetivo de evitar a expropriação pelos gestores e acionistas controladores. Dentre as práticas associadas a esse tema, estão a transparência, a equidade de tratamento dos acionistas e a prestação de contas. (CVM, 2002).

Sob outra perspectiva, Shleifer e Vishny (1997) definem que a GC lida com as maneiras pelas quais os fornecedores de recursos garantem que obterão para si o retorno sobre seu investimento. Nesse sentido, a maior concentração de propriedade e a menor proteção aos investidores minoritários presentes em mercados como o brasileiro (La Porta, et al.,2002) evidenciam um cenário propício à maior preocupação com questões relativas à GC.

Quanto aos dividendos, sabe-se que, no mercado de capitais brasileiro, tem-se a figura do dividendo mínimo obrigatório, como forma de distribuição de riqueza por parte das organizações, a fim de garantir minimamente o retorno do investimento ao acionista. Ante a esta e às demais particularidades existentes quanto à forma de distribuição de lucros aos acionistas no país, incluindo a existência de juros sobre capital próprio' (Forti; Peixoto; Alves, 2015), a diferenciação de ações em ordinárias e preferenciais (Martins; Famá, 2012, Gorga, 2004) e a concentração acionária (Guimarães; Marques; Peixoto, 2014 e Sonza; Kloeckner, 2014), os estudos internacionais se tornam pouco aderentes ao contexto brasileiro.

Dessa forma, a fim de relacionar a distribuição de dividendos e a GC com ênfase no cenário nacional, tem-se como o problema da presente pesquisa: qual o efeito da governança corporativa na distribuição de dividendos aos acionistas das companhias não financeiras listadas na BM\&F Bovespa, de 2002 a 2013 ?

Propõe-se enquanto objetivo deste artigo, avaliar o efeito da governança corporativa na distribuição de dividendos aos acionistas das companhias listadas na BM\&F Bovespa. Como hipótese, espera-se que seja obtido um efeito positivo da governança corporativa na distribuição de dividendos aos acionistas, corroborando o estudo de Jiraporn, Kim e Kim (2011), cujos resultados apontam que empresas com melhores práticas de governança corporativa pagam dividendos maiores do que aquelas com práticas de governança incipientes.

A escolha das companhias nacionais para o desenvolvimento da pesquisa contou com uma amostra de 233 empresas correspondentes às não financeiras cujos ativos são listados na Bolsa de Valores, Mercadorias e Futuros de São Paulo - BM\&FBovespa, obedecendo a um filtro de liquidez. Incluem os ativos que se enquadram nos níveis 1, 2 e no Novo Mercado de GC, bem como aquelas classificadas no mercado tradicional, tomando por base os dados da própria instituição. O período estudado envolve 
os anos de 2002 a 2013, contemplando todo intervalo desde a definição dos níveis de Governança Corporativa pela CVM até o presente estudo, incluindo dados disponíveis na base de dados Economática.

Quanto aos aspectos metodológicos, aplicou-se a regressão com dados em painel na série de dados. A variável GC constitui-se a variável teste desta pesquisa e refere-se à representação dos níveis diferenciados de governança corporativa das empresas listadas na BM\&F Bovespa. CRASH é a variável de controle que indica presença ou não de crise no mercado durante o período. Esta variável foi incluída em virtude das ocorrências macroeconômicas compreendidas no intervalo adotado e tornou-se o diferencial do estudo, dada a escassez de trabalhos que contemplem, além de crise, dividendos e GC na BM\&F Bovespa simultaneamente. A variável dependente da pesquisa é DPA, que corresponde ao montante de dividendos por ação distribuído aos acionistas no período.

Os resultados da pesquisa apontaram para uma relação positiva e significativa entre os níveis mais altos de GC da BM\&F Bovespa e a distribuição de lucros através de dividendos. Os testes de Breusch-Pagan e Hausman foram aplicados para determinar o melhor caminho metodológico a ser seguido e foi utilizado o software Stata na análise econométrica.

A estrutura do artigo contempla, além desta introdução, o referencial teórico, que será apresentado na segunda seção e a metodologia, na terceira. A quarta seção apresenta a análise dos resultados encontrados, ao passo que na quinta e sexta seções estarão detalhadas, respectivamente, as considerações finais a respeito do estudo desenvolvido e as referências utilizadas para tal. 


\section{REFERENCIAL TEÓRICO}

A seguir, serão detalhados alguns estudos de âmbito nacional e internacional bem como seus resultados relativos à análise de dividendos e governança corporativa. Nota-se, pelo exposto, que há dualidade nas conclusões, o que torna plausível nova pesquisa a respeito do tema, voltado para o mercado nacional.

\subsection{POLÍTICA DE DIVIDENDOS}

Dividendos são proventos pagos pelas empresas aos seus acionistas, figurando, portanto, como uma das formas de distribuição de lucros aos investidores. A política de dividendos representa as decisões tomadas pelos administradores da companhia em relação ao pagamento ou não de dividendos, contemplando, principalmente, a frequência de pagamentos; a necessidade de capital para novos investimentos na empresa; as fontes de capital disponíveis e seu respectivo custo; a preferência dos acionistas em receber rendimentos regulares ou futuros e o percentual do lucro a ser distribuído aos acionistas (Novis Neto, 2002).

Em 1961, a Teoria da Irrelevância dos Dividendos foi desenvolvida por Modigliani e Miller. Neste trabalho, os autores se propuseram a analisar o processo de avaliação de empresas considerando o efeito da política de dividendos no preço da ação. Partindo como princípio básico de valuation que o preço de cada ação deve ser tal que a taxa de retorno, composta por dividendos mais ganho de capital por dólar investido, seja o mesmo para todo o mercado em qualquer intervalo de tempo, Modigliani e Miller (1961) chegam à conclusão de que o dividendo afeta duplamente o preço da ação.

Assim, Modigliani e Miller (1961) consideram que, em um mercado ideal, a interferência positiva e negativa do dividendo devem se anular, fazendo com que o preço da ação não seja afetado pela decisão de dividendos atual ou futura. Por outro lado, outras teorias foram elaboradas, defendendo a influência positiva da política de dividendos na avaliação das empresas. Nesse sentido, Gordon (1963) defende a relevância da política de dividendos, alegando que os acionistas mais cautelosos preferem o recebimento de dividendos correntes, elevando, assim, os preços das ações.

La Porta, et al. (2000) destacam que a política de investimentos de uma empresa não pode ser elaborada de forma independente da política de dividendos. Nessa pesquisa, envolvendo 4000 empresas de 33 países diferentes, foram analisados os problemas de agência inerentes à decisão de se distribuir dividendos, no intervalo entre 1989 e 1994. Como resultado, foi observado que a política de distribuição de dividendos varia de acordo com a legislação de cada país (common law ou civil law) e que uma maior distribuição de dividendos foi observada em países com fraca proteção legal aos acionistas.

Bruni, et al. (2003) corroboram com este estudo ao sugerirem que a política de dividendos se mostra mais relevante em países com fraca proteção legal aos acionistas. Nesta pesquisa a proteção legal é apresentada de acordo com a tributação sobre a remuneração dos acionistas: nos de forte proteção, como os Estados Unidos, os ganhos de capital e os dividendos são ambos tributados; já naqueles em que a proteção aos acionistas é fraca, como no Brasil, a tributação incide somente sobre ganhos de capital e os dividendos são isentos.

Além disso, no cenário brasileiro, ainda que a empresa enquanto Sociedade Anônima (S.A.) consiga formular sua própria política de dividendos, conforme legislação (exceto se o estatuto da empresa 
estabelecer outra condição) fica estabelecido um dividendo mínimo obrigatório ao acionista de 25\% sobre o lucro líquido ajustado (Lei 6.404/1976).

A temática de dividendos e de políticas de distribuição de proventos vem sendo objeto de estudo há pelo menos cinco décadas. Diversas teorias e estudos empíricos sobre os possíveis efeitos da política de dividendos no valor da empresa e retorno das ações foram elaborados. Como exemplos destas teorias, têm-se a Teoria da Substituição dos Dividendos e a Teoria do Pássaro na Mão (Bird-in-the-hand Theory). Para a primeira, um dos estudos é o de Sawicki (2009), no qual, enfatizando o contexto de crise entre os anos de 1994 e 2003, encontraram-se evidências com empresas de cinco países emergentes do sudeste asiático de que os dividendos atuariam como substitutos para outros mecanismos de GC.

A respeito da Teoria do Pássaro na Mão, parte-se do pressuposto de que o risco inerente ao dividendo é menor que aquele atrelado ao ganho de capital, dada a associação deste a uma data futura (Martins; Famá, 2012). Os estudos de Lintner (1956) e Gordon (1959) também são referências e neles observa-se que, conforme aumenta a distribuição de dividendos aos acionistas, o retorno que eles têm é reduzido quando comparado a eventuais ganhos de capital ou valorização da ação, justamente pelo fato da incerteza dos acionistas ser maior no futuro.

Presume-se assim que, ainda que o dividendo represente uma distribuição de lucros menor comparada a um eventual ganho futuro (Teoria do Pássaro na Mão), os acionistas preferirão garanti-la, implicando em possíveis variações no nível de risco da empresa na qual se investe. (Zagonel, 2013).

\subsection{GOVERNANÇA CORPORATIVA}

Embora o conceito de GC exista há mais de 50 anos, Carvalhal da Silva (2004) argumenta que somente nos últimos anos as preocupações inerentes a ele vêm se transformando em questões relevantes.

Neste contexto, abordagens como a da teoria de agência passam a ser evidenciadas. Apresentada no artigo seminal de Jensen e Meckling (1976), esta teoria trata das relações de conflito de interesse entre acionistas e gestores, quando estes, diante do contexto de separação de propriedade, procuram particularmente a maximização de suas próprias riquezas. Partindo dessa teoria, à medida que os gestores priorizam o aumento da sua riqueza particular, as decisões relativas às organizações podem estar enviesadas a este objetivo e não contribuírem para o desempenho global da firma, o que refletiria em alterações nos recursos disponíveis para distribuição aos acionistas.

Inerente ainda ao contexto da teoria de agência, a hipótese da assimetria informacional merece destaque. Myers e Majluf (1984) abordam essa hipótese em seu artigo seminal, destacando que os gestores conhecem mais sobre o valor e o desempenho das empresas do que os potenciais investidores. Segundo Martins e Famá (2012), a assimetria de informações surge da constatação de que os gestores detêm mais informações sobre as perspectivas relativas aos investimentos e dividendos que os (demais) acionistas. Nesse contexto, que é o de surgimento da GC, a distribuição de dividendos para os acionistas seria uma forma de diminuir os conflitos entre esses agentes. Especificamente no Brasil, Moreiras, Tambosi Filho e Garcia (2009), ao analisar 360 empresas entre os anos de 2000 a 2007, ressaltam a relevância da política de dividendos, ao constatarem que, na comparação entre as empresas listadas nos níveis diferenciados de GC da BM\&F Bovespa e as do mercado tradicional, a assimetria de informações é maior no segundo grupo.

Silva (2003), por sua vez, relaciona o fluxo de caixa gerado pela empresa e a distribuição de dividendos. Em sua pesquisa junto a 71 companhias brasileiras listadas na BM\&F Bovespa entre 1998 e 2001, analisando a influência dos custos de agência nos dividendos através de regressão OLS, verificou-se 
que a existência ou o maior volume de fluxo de caixa livre gerado pela firma, associados a poucas oportunidades de investimento, sugere um maior montante de pagamentos em dividendos, de forma a minimizar os conflitos de agência.

Outra vertente dos conflitos de agência é a do tipo minoritário-majoritário, apontada por Claessens, et al. (2002), como o principal conflito na maioria dos países, com exceção dos EUA. Sonza e Kloeckner (2014) argumentam que, no Brasil, esta é a forma mais comum dos conflitos de agência em virtude da concentração de propriedade característica nas empresas e da sobreposição com a gestão. De acordo com Procianoy (1996), Silva (2004) e Bellato, Silveira e Savoia (2006), a presença de acionistas majoritários detentores do controle das organizações, associada à existência das duas classes de ações no Brasil - com e sem direito a voto - (Martins, Famá, 2012) direcionam ainda mais os ditos conflitos de agência para a relação entre majoritários e minoritários em detrimento das divergências entre acionistas e gestores.

Nesse sentido, Carvalhal da Silva (2004), ao analisar os efeitos da estrutura de controle e propriedade no valor de mercado, na estrutura de capital e na política de dividendos de 225 empresas brasileiras no ano de 2000, formula, em duas de suas oito hipóteses a relação entre concentração de direitos de voto e payout. Segundo seus resultados, a política de dividendos pode ser considerada uma forma de estabelecer uma melhor reputação da empresa diante dos acionistas minoritários, diminuindo a expropriação dos majoritários sobre estes e, consequentemente, minimizando tais conflitos.

Os conflitos de agência tendem a se ampliar no cenário de países com leis mais fracas e enforcement deficiente, como o Brasil (La Porta et al., 2002) e, seja pelos custos incorridos para controlá-los, ou pelo risco da expropriação dos acionistas minoritários pelos majoritários, entende-se que os dividendos são mais valorizados pelos acionistas.

\subsection{GOVERNANÇA CORPORATIVA E DIVIDENDOS}

A análise da relação entre GC e dividendos é recorrente tanto nos estudos nacionais quanto internacionais. Nas pesquisas, observa-se que os mecanismos de GC - conselhos de administração, estrutura de propriedade e controle, proteção aos minoritários, transparência e compensação aos gestores - são relacionados com medidas como payout ou mesmo com a probabilidade de pagamento de dividendos.

No Quadro 1 apresentado abaixo, estão sumarizadas algumas pesquisas, bem como seus principais resultados no âmbito de GC e dividendos: 
Quadro 1: Estudos nacionais e internacionais sobre Governança Corporativa e Dividendos

\begin{tabular}{|c|c|c|c|c|}
\hline & Autor(es) & Período analisado & Amostra & Principais resultados \\
\hline & $\begin{array}{l}\text { Moreiras, Tambosi Filho } \\
\text { e Garcia (2009) }\end{array}$ & 2000 a 2007 & $\begin{array}{l}360 \text { empresas } \\
\text { com ações mais } \\
\text { negociadas na } \\
\text { BM\&F Bovespa }\end{array}$ & $\begin{array}{l}\text { As empresas do novo mercado são diferentes das empresas do mercado } \\
\text { tradicional. No que se refere à política de dividendos, os mercados não se } \\
\text { comportam de maneira semelhante, fazem parte de populações distintas. } \\
\text { As empresas no mercado tradicional têm taxa de diminuição do payout } \\
\text { maior; o aumento do lucro não é repassado via dividendos e elas têm } \\
\text { maiores dificuldades para alterar a política de dividendos. }\end{array}$ \\
\hline & Zagonel (2013) & 1986 a 2011 & $\begin{array}{l}672 \text { empresas } \\
\text { negociadas na } \\
\text { BM\&F Bovespa }\end{array}$ & $\begin{array}{l}\text { As empresas do novo mercado são diferentes das empresas do mercado } \\
\text { tradicional. No que se refere à política de dividendos, os mercados não se } \\
\text { comportam de maneira semelhante, fazem parte de populações distintas. } \\
\text { As empresas no mercado tradicional têm taxa de diminuição do payout } \\
\text { maior; o aumento do lucro não é repassado via dividendos e elas têm } \\
\text { maiores dificuldades para alterar a política de dividendos. }\end{array}$ \\
\hline & $\begin{array}{l}\text { Bachmann, Azevedo e } \\
\text { Clemente (2012) }\end{array}$ & 2001 a 2010 & $\begin{array}{l}219 \text { empresas na } \\
\text { BM\&F Bovespa }\end{array}$ & $\begin{array}{c}\text { Não importa, quanto à regularidade de pagamento de dividendos, em } \\
\text { qual nível de GC a empresa está enquadrada, exceto para pagamento a } \\
\text { acionistas preferenciais. Importa apenas se está enquadrada em algum } \\
\text { nível e por quanto tempo (consistência da governança). Quanto maior o } \\
\text { tempo de enquadramento em qualquer nível diferenciado de GC, menor } \\
\text { a regularidade no pagamento de dividendos. }\end{array}$ \\
\hline & Ribeiro, et al. (2013) & 2011 & $\begin{array}{c}259 \text { empresas } \\
\text { listadas na BM\&F } \\
\text { Bovespa }\end{array}$ & $\begin{array}{l}\text { Ainda que, do ponto de vista descritivo, exista diferença no yield entre } \\
\text { empresas que possuem práticas de GC (maiores) e as que não (menores), } \\
\text { não há associação significante entre práticas mais rigorosas de GC e a } \\
\text { política de distribuição de dividendos. }\end{array}$ \\
\hline 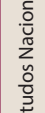 & Mehar (2005) & 1981 a 2002 & $\begin{array}{c}180 \text { empresas } \\
\text { listadas no } \\
\text { Paquistão }\end{array}$ & $\begin{array}{l}\text { Governança Corporativa tem relações significativas com a Política de } \\
\text { Dividendos. Relação negativa entre liquidez e dividendos, indicando } \\
\text { a importância dos dividendos na determinação do capital de giro. Se } \\
\text { a empresa tem grande concentração de propriedade nas mãos dos } \\
\text { diretores, as chances de ocorrência de dividendos são maiores. }\end{array}$ \\
\hline & $\begin{array}{l}\text { Kowalewski, Stetsyuk, } \\
\text { Talavera (2007) }\end{array}$ & 1998 a 2004 & $\begin{array}{l}110 \text { empresas na } \\
\text { Polônia }\end{array}$ & $\begin{array}{c}\text { O aumento no índice de transparência leva a aumento na proporção } \\
\text { dos pagamentos em dividendos. As empresas com fracos direitos aos } \\
\text { minoritários pagam dividendos menos expressivos do que as firmas com } \\
\text { altos padrões de governança. Associação positiva e significativa entre a } \\
\text { distribuição de dividendos e práticas de governança corporativa, o que } \\
\text { indica que as empresas pagam dividendos mais elevados se os direitos } \\
\text { dos acionistas estão melhor protegidos. Em empresas prestadoras de } \\
\text { fortes direitos dos minoritários, o poder é muitas vezes utilizado para } \\
\text { extrair dividendos. }\end{array}$ \\
\hline & Dutta e Chang (2012) & 1997 a 2004 & $\begin{array}{l}\text { Empresas } \\
\text { Canadenses }\end{array}$ & $\begin{array}{c}\text { O maior tamanho do Conselho de Administração (CA) o torna } \\
\text { menos eficaz e, portanto, reflete práticas de governança mais fracas. } \\
\text { Corroborando a Teoria da Substituição dos Dividendos, constatou-se que } \\
\text { empresas com governança mais fraca (CA's maiores) tendem a pagar } \\
\text { maiores dividendos. }\end{array}$ \\
\hline & Gill e Obradovich (2012) & 2009 a 2011 & $\begin{array}{l}296 \text { empresas } \\
\text { cotadas na bolsa } \\
\text { de Nova York }\end{array}$ & $\begin{array}{l}\text { Quando tamanho da empresa, desempenho, alavancagem e crescimento } \\
\text { são mantidos constantes, a decisão de pagar dividendos tem relação } \\
\text { positiva com o tamanho do conselho, com a dualidade de papéis do CEO } \\
\text { e internacionalização. Existe uma relação negativa com a propriedade } \\
\text { institucional, exemplificada por alta porcentagem de participação por } \\
\text { instituiçôes como fundos no capital da empresa. }\end{array}$ \\
\hline & O'Connor (2012) & 2001 & $\begin{array}{l}220 \text { empresas } \\
\text { em } 21 \text { mercados } \\
\text { emergentes }\end{array}$ & $\begin{array}{c}\text { O modelo de pagamento de dividendos, que prevê crescimento do } \\
\text { payout de acordo com o fortalecimento dos direitos dos acionistas, } \\
\text { prevalece ao longo do ciclo de vida da empresa, mas somente quando } \\
\text { os direitos dos acionistas são fortes. Não há evidência do modelo de } \\
\text { substituição de dividendos. }\end{array}$ \\
\hline
\end{tabular}

A partir da literatura, procurou-se analisar se há uma relação positiva entre distribuição de dividendos e GC. Pressupõe-se que a GC tenta minimizar os efeitos do risco, da assimetria informacional e dos conflitos de agência entre os acionistas majoritários e minoritários. Dessa forma, a GC e o conjunto de mecanismos compreendido nela atuam monitorando a gestão e, assim procuram alinha-la aos interesses dos proprietários (Almeida; Santos, 2008).

Sob essa óptica, Jiraporn, Kim e Kim (2011), em sua pesquisa envolvendo as empresas reportadas pelo Institutional Shareholder Services Inc. (ISS) entre 2001 e 2004 - mais de 5000 em todo o mundo analisam variáveis nível firma (dentre as quais tamanho, alavancagem rentabilidade, lucros acumulados); nível país (proporção do imposto de renda sobre os ativos totais) e; de governança (índice construído a partir de categorias de GC tais como CA, auditoria, remuneração dos executivos e propriedade). Através de regressões LOGIT, os autores destacam como resultado que acionistas de empresas com GC forte conseguem forçar os gestores a remunerá-los sob a forma de dividendos, reduzindo a possibilidade de utilização indevida do fluxo de caixa livre.

Dessa forma, considera-se que em níveis diferenciados de GC os gestores trabalhem com uma maior distribuição de dividendos, fundamentando a elaboração da seguinte hipótese:

20 dividendo Yield representa a relação dos proventos pagos no ano equivalente ao montante de dividendos e juros sobre capital próprio e o preço da ação no final do ano (Ribeiro, et al., 2013, p.7). 
H1: Há uma relação positiva entre a qualidade da governança corporativa e a distribuição de dividendos aos acionistas das companhias listadas na BM\&F Bovespa.

Por outro lado, com a GC mitigando o risco, a assimetria informacional e os conflitos de agência, supõe-se que as empresas pertencentes aos níveis de GC da BM\&F Bovespa sejam mais transparentes e apresentem menor risco, sobretudo em aspectos de gestão, o que poderia levar à redução do pagamento de dividendos (efeito contrário), já que a GC compensaria a necessidade de pagar dividendos (efeito substituição). Os resultados de Forti, Peixoto e Alves (2015) seguem essa linha: pesquisando os determinantes do pagamento de dividendos no Brasil com uma amostra de 300 empresas entre os anos de 1995 e 2011 e utilizando regressões por mínimos quadrados ordinários, efeitos fixos, Tobit e GMM, os autores constataram relação inversa e significante entre o pagamento de dividendos e o fato de as empresas serem signatárias do nível mais alto de GC da BM\&F Bovespa.

Partindo-se desses pressupostos e constatações, cria-se outra hipótese para a resposta da questão de pesquisa:

H2: Há uma relação negativa entre a qualidade da governança corporativa e a distribuição de dividendos aos acionistas das companhias listadas na BM\&F Bovespa.

Com a adoção das práticas de GC pelas empresas listadas nos níveis diferenciados, os investidores tenderiam a demandar menor remuneração e consequentemente menos dividendos, entendendo haver menos risco quando o investimento tem tal característica. 


\section{METODOLOGIA}

A classificação da presente pesquisa quanto aos objetivos é descritiva. No que tange à abordagem do problema proposto, a mesma é classificada como quantitativa. A população de estudo é composta por todas as empresas listadas na BM\&F BOVESPA. A amostra, entretanto, foi definida pelas companhias não financeiras, contemplando o período de 2002 a 2013, de forma a abranger todo o intervalo desde a definição dos níveis de GC pela CVM no país. A exclusão do setor financeiro foi realizada devido às particularidades da estrutura de capital deste setor (e seus possíveis impactos na distribuição dos dividendos), conforme os estudos de Forti, Peixoto e Alves (2015) e Forti e Schiozer (2015).

Os dados econômico-financeiros das empresas estudadas, dentre os quais os dividendos anuais pagos por ação, foram coletados através da base de dados Economática ${ }^{\oplus}$. Cabe reiterar que, por limitações técnicas da versão disponível da base de dados à época da pesquisa, na coleta dos valores desta variável foi considerada a distribuição de recursos tanto via distribuição de dividendos quanto através de juros sobre capital próprio. Em paralelo, recorreu-se ao site da BM\&F Bovespa para coleta da classificação das empresas de acordo com o nível de GC.

Aplicou-se à população investigada o filtro de liquidez sugerido por Silveira (2004) e, dessa forma, foram selecionadas apenas as empresas com liquidez significativa, ou seja, aquelas com índice de liquidez anual maior que $0,001 \%$ do índice correspondente à empresa com ações mais líquidas em 2013 e assim sucessivamente para os anos anteriores até 2002.

A fim de se estabelecer uma relação entre a distribuição de dividendos e as práticas de GC no Brasil, na amostra abordou-se tanto os ativos que se enquadram nos níveis 1, 2 e no Novo Mercado de GC, quanto os classificados no mercado tradicional. Para que tal relação pudesse ser verificada, foi criada uma dummy relativa à classificação das empresas quanto aos níveis diferenciados de GC da BM\&F Bovespa e, seguindo o modelo de Carvalhal da Silva e Chien (2013), os níveis mais avançados de GC foram agrupados: Nível 2 e Novo Mercado. Utilizou-se da Análise de Dados em Painel, tendo por base um painel desbalanceado oriundo do filtro de liquidez aplicado à amostra e também dos missing values. Quanto à melhor forma de lidar com a heterogeneidade dos dados - efeitos fixos ou efeitos aleatórios - (STOCK; WATSON, 2004), foram aplicados os testes Breusch-Pagan e Hausman, para determinar o melhor caminho metodológico a ser seguido.

O modelo econométrico proposto, tendo por base as pesquisas de Jiraporn, Kim e Kim (2011) e Forti, Peixoto e Alves (2015) foi:

$\mathrm{DPA}_{\mathrm{it}}=\beta_{0}+\beta_{1}\left(\mathrm{GC}_{\mathrm{itt}}+\beta_{2}\left(\mathrm{TAM}_{\mathrm{it}}\right)+\beta_{3}\left(\mathrm{ALAV}_{\mathrm{it}}\right)+\beta_{4}\left(\mathrm{ROA}_{\mathrm{it}}\right)+\beta_{5}\left(\mathrm{DPAEA}_{\mathrm{it}}\right)+\beta_{6}\left(\mathrm{Q}_{\mathrm{it}}\right)+\beta_{7}\left(\mathrm{SET}_{\mathrm{it}}\right)+\beta_{8}\left(\mathrm{MTB}_{\mathrm{it}}\right)\right.$ $+\beta_{9}\left(\right.$ Beta $\left._{\text {it }}\right)+\beta_{10}\left(\right.$ CRES $\left._{\text {it }}\right)+\beta_{11}($ CRASH $)+\beta_{11}($ ANO $)+\varepsilon_{\text {it }}$

$\mathrm{Na}$ elaboração do modelo, considerou-se a variável Dividendos Por Ação (DPA) como variável dependente, consistindo no montante, em reais por cada ação, que a empresa distribuiu aos seus acionistas sobre a forma de dividendos relativamente aos resultados gerados no exercício. Para as variáveis independentes, levaram-se em consideração estudos anteriores, bem como os resultados encontrados pelos respectivos autores, conforme sumarizam os dados apresentados no Quadro 2. A coleta de dados foi feita com o filtro padrão do Economática, mostrando apenas uma classe de ações por empresa: aquela com maior volume no último mês. 
Quadro 2: Variáveis Independentes

\begin{tabular}{|c|c|c|c|c|c|}
\hline TIPO & NOME & DESCRIÇÃO & FÓRMULA / DEFINIÇÃO & $\begin{array}{l}\text { SINAL } \\
\text { ESPERADO }\end{array}$ & AUTORES \\
\hline 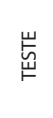 & GC & $\begin{array}{l}\text { Empresas } \\
\text { participantes dos } \\
\text { níveis de GC da } \\
\text { BM\&FBovespa }\end{array}$ & $\begin{array}{c}\text { Dummy para os níveis diferenciados: } 0 \text { para } \\
\text { mercado tradicional e Nível } 1 ; 1 \text { para Nível } 2 \\
\text { e Novo Mercado. }\end{array}$ & $(+)$ & $\begin{array}{c}\text { Jensen (1986), Renneboog } \\
\text { e Szilagyi (2006), Michaely e } \\
\text { Roberts (2006), La Porta et al. } \\
\text { (2000); Jiraporn, Kim e Kim } \\
\text { (2011) }\end{array}$ \\
\hline \multirow{10}{*}{ 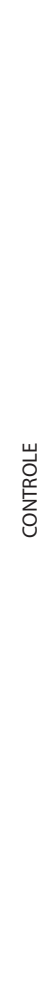 } & TAM & Tamanho & Logaritmo Natural do Ativo Total & $(+)$ & $\begin{array}{c}\text { Fatemi e Bildik (2012); } \\
\text { Renneboog e Trojanowski } \\
\text { (2011); Moh'd, Perry e Rimbey } \\
\text { (1995). }\end{array}$ \\
\hline & ALAV & Alavancagem & Endividamento: Passivo Total / PL & $(+/-)$ & $\begin{array}{l}\text { (+) La Porta et al (2000); } \\
\text { (-)Jiraporn, Kim e Kim (2011); }\end{array}$ \\
\hline & ROA & $\begin{array}{l}\text { Rentabilidade } \\
\text { (Retorno sobre os } \\
\text { ativos). }\end{array}$ & Resultado Operacional / Ativo Total & $(+)$ & $\begin{array}{l}\text { Aivazian, Booth e Cleary (2003); } \\
\text { Kania e Bacon (2005); John e } \\
\text { Knyazeva (2006); Lintner (1956). }\end{array}$ \\
\hline & DPAEA & $\begin{array}{l}\text { Dividendos Pagos } \\
\text { no Exercício Anterior }\end{array}$ & $\begin{array}{l}\text { Montante que as empresas distribuíram aos } \\
\text { acionistas, por cada ação, sobre a forma de } \\
\text { dividendos no exercício anterior. }\end{array}$ & $(+)$ & $\begin{array}{c}\text { Lintner (1956), Arrazola, Hevia } \\
\text { e Mato (1992), Bagüés e Fumás } \\
\text { (1995), Escuer e Cabestre (1995), } \\
\text { Benzinho (2007), Sanchéz } \\
\text { (2007). }\end{array}$ \\
\hline & Q & Q de TOBIN & $\begin{array}{l}\text { Oportunidades de investimento: } \\
\mathrm{Q}=(\mathrm{VMAO}+\mathrm{VMAP}+\mathrm{DIVT}) / \mathrm{AT} ; \mathrm{VMAO}=\text { valor de } \\
\text { mercado das ações ordinárias; } \mathrm{VMAP}=\text { valor } \\
\text { de mercado das ações preferenciais; } \\
\text { DIVT=valor contábil do exigível total }(\mathrm{PC}- \\
\mathrm{AC}+\mathrm{ELP}+\mathrm{Estoque}) ; \mathrm{AT}=\text { Ativo Total. }\end{array}$ & $(-)$ & $\begin{array}{l}\text { Silveira e Bellato (2006); Forti, } \\
\text { Peixoto e Alves (2015); Rozeff } \\
\text { (1982). }\end{array}$ \\
\hline & SET & Setor & Classificação dos setores no Economática & Indeterminado & $\begin{array}{l}\text { Silveira e Bellato (2006); Forti, } \\
\text { Peixoto e Alves (2015); Rozeff } \\
\text { (1982). }\end{array}$ \\
\hline & MTB & Market-to-book & $\begin{array}{l}\text { Valor de mercado ajustado dividido pelo } \\
\text { valor contábil da firma (PL). }\end{array}$ & $(+)$ & $\begin{array}{l}\text { Forti, Peixoto e Alves (2015). } \\
\text { Lintner (1956). }\end{array}$ \\
\hline & Beta & Beta & Risco sistemático (coletado no Economática) & $(-)$ & Forti, Peixoto e Alves (2015) \\
\hline & CRES & $\begin{array}{l}\text { Crescimento dos } \\
\text { Lucros }\end{array}$ & $\begin{array}{c}\text { (Lucro Atual - Lucro Ano Anterior) / Lucro } \\
\text { Ano Anterior }\end{array}$ & $(+)$ & $\begin{array}{l}\text { Lintner (1956); Forti, Peixoto e } \\
\text { Alves (2015). }\end{array}$ \\
\hline & CRASH & $\begin{array}{l}\text { Variável indicando } \\
\text { períodos de crise }\end{array}$ & $\begin{array}{c}\text { Dummy para sinalizar períodos de Crise: } 0 \\
\text { para não crise; } 1 \text { para crise. }\end{array}$ & $(+)$ & Deucort e Procianoy (2012) \\
\hline & ANO & Ano & Dummy para o ano & Indeterminado & \\
\hline
\end{tabular}

Para a variável teste - GC, espera-se relação positiva e significante com DPA, embasada na teoria do Fluxo de Caixa Livre (Jensen, 1986), segundo a qual, gestores de empresas com governança fraca são mais propensos a reter dinheiro dentro da empresa, uma vez que lhes permite o consumo em gratificações; envolver-se e investir em projetos e aquisições que podem aumentar o seu prestígio pessoal, mas não necessariamente proporcionar retorno aos acionistas. Por sua vez, em empresas com forte governança, a diretoria é menos propensa a abusar do fluxo de caixa livre, aumentando, assim, a atratividade de pagamento de dinheiro aos acionistas (dividendos). Estudos que corroboram com tal ideia são Jiraporn, Kim e Kim (2011), Renneboog e Szilagyi (2006), Michaely e Roberts (2006) e La Porta et al. (2000).

Como controle da relação entre GC e distribuição de dividendos, utilizou-se de outras variáveis do nível da firma. O tamanho (TAM) foi medido pelo logaritmo natural do ativo total e, considerando que firmas maiores têm maior propensão a pagar dividendos (Fatemi, \& Bildik, 2012; Renneboog \& Tro Janowski, 2011; Moh’D, Perry \& Rimbey, 1995), espera-se haver relação positiva entre esta variável e a variável dependente DPA. Outra variável de controle para a qual se espera relação positiva com o volume de dividendos pagos é o ROA, medido neste estudo pela relação entre o Resultado Operacional e o Ativo Total. Isto é, empresas com maior lucratividade tendem a pagar mais dividendos aos acionistas. A escolha do ROA objetiva analisar o desempenho da organização sem o impacto das despesas financeiras no resultado e, além disso, evitar eventuais problemas de multicolinearidade com a variável CRES, a qual leva em consideração o Lucro Líquido. 
Para a variável CRES, também se espera relação positiva e significante com DPA, tendo por base que o crescimento do lucro denota menor incerteza quanto à operação futura da companhia e, com isso, diminui a insegurança dos gestores para a distribuição de dividendos no momento presente. Quando as empresas apresentam maior lucratividade, os gestores sentem-se mais confortáveis com o pagamento de dividendos (Lintner,1956).

As demais variáveis para as quais se espera encontrar relação positiva e significante na análise são DPAEA, MTB e CRASH. Quanto à primeira, Lintner (1956) destaca que os gestores são relutantes em aumentar os dividendos no presente e ter que reduzi-los no futuro, mesmo quando a empresa apresenta resultados compatíveis para esta redução, consequentemente, espera-se que empresas que tenham apresentado fluxos consideráveis de dividendos no exercício anterior, mantenham tal patamar, sobretudo no mercado brasileiro, dada a característica e a diferenciação de alguns setores pelo histórico de maiores dividendos. Em termos de Market-to-book, a razão entre o valor de mercado ajustado da empresa e seu valor contábil evidencia a valorização da empresa pelo mercado e, de acordo com Lintner (1956), o mercado paga um prêmio (valoriza) empresas que pagam mais dividendos aos seus acionistas. A terceira variável - CRASH - foi introduzida com o intuito de se medir o comportamento da distribuição de dividendos em períodos de crise. Conforme Deucort e Procianoy (2012), que analisaram o processo decisório da distribuição de dividendos nas empresas brasileiras através de entrevistas diretas aos seus CFO's, em intervalos de crise as organizações teriam maior propensão em pagar dividendos como forma de se manterem atrativas para os investidores do mercado. Para a determinação dos períodos de crise, adotou-se os critérios de Peixoto et al. (2013), selecionado os anos de 2002, cuja crise foi motivada por eventos como a mudança no governo federal brasileiro; 2008 e 2009 nos quais a crise foi de âmbito internacional decorrente dos efeitos do subprime americano (Vidal, 2011).

As variáveis $Q$ de Tobin e Beta também foram introduzidas no modelo, porém para estas, a expectativa é de uma relação negativa e significante. Isto, respectivamente, pelo fato de que as boas oportunidades de investimento tendem a diminuir a taxa de pagamento de dividendos, direcionando os recursos para tais fins e; pelo fato de quanto maior o risco inerente à organização, menor a disponibilidade de recursos para distribuição, ou seja, no caso do beta, o comprometimento financeiro no contexto de risco inibiria a distribuição de dividendos (Silveira \& Bellato, 2006; Forti, Peixoto \& Alves, 2015; Rozeff,1982).

Para a variável alavancagem, a relação esperada não pode ser claramente definida. A literatura sugere um comportamento dúbio desta variável ante à distribuição de dividendos, da seguintes forma: considerando o efeito sinalização (Lopez-de-Silanes, Vishny \& Shleifer, 2000), empresas que se endividam, sinalizam investimentos futuros e tendem a pagar mais dividendos, confirmando sua expectativa de crescimento. Desta forma espera-se haver relação positiva. Por outro lado, Jiraporn, Kim e Kim (2011) corroborando com a Teoria de Agência identificaram que o endividamento funcionaria para a empresa como um mecanismo de redução dos custos de agência, à medida que lhe proporcionaria menor fluxo de caixa livre; submeter-Ihe-ia a covenants restritivos e consequentemente, implicaria na redução dos recursos disponíveis para distribuição via dividendos. Tem-se dessa forma uma expectativa de sinal negativo na relação.

Por fim, o modelo também foi controlado por ano e setor, sendo adotada para este último, a classificação da base Economática ${ }^{\circledR}$. As empresas que não apresentaram as informações disponíveis foram eliminadas, e, ao todo, foram obtidas 1001 observações. Os outliers foram devidamente tratados com a técnica de winsorização a fim de evidenciar melhor os efeitos sobre as variáveis. Os dados gerados foram analisados utilizando o software Stata ${ }^{\circledR} 11$. 


\section{ANÁLISE DOS RESULTADOS}

Os resultados obtidos através da pesquisa empírica são apresentados nesta seção, em primeiro lugar com a análise descritiva dos dados e em segundo lugar com as análises da regressão, após a realização de alguns testes.

A análise descritiva das informações está evidenciada na Tabela 1, na qual se verifica o número de observações, a média, o desvio padrão, o menor e o maior valor de cada variável.

Tabela 1: Análise descritiva das variáveis

\begin{tabular}{|c|c|c|c|c|c|}
\hline Variáveis & Observações & Média & Desvio Padrão & Mínimo & Máximo \\
\hline DPA & 1001 & 0,9213335 & 2,536267 & 0,0000 & 48,0941 \\
\hline TAM & 1000 & 14,68243 & 2,278902 & 4,7362 & 20,5846 \\
\hline ALAV & 1000 & 2,344806 & 17,0505 & $-274,9095$ & 253,5058 \\
\hline ROA & 943 & 0,0846796 & 0,3677154 & $-7,3772$ & 0 \\
\hline DPAEA & 949 & 0,9695632 & 2,664426 & 3,6438 & 48,0941 \\
\hline Q & 996 & 3,635307 & 35,48826 & $-0,1663$ & 992,9035 \\
\hline BETA & 854 & 0,7142389 & 0,4738947 & $-0,99$ & 2,96 \\
\hline MTB & 996 & 2,163544 & 7,334556 & $-99,4033$ & 78,2482 \\
\hline CRESC & 930 & - & 13,66148 & $-339,7068$ & 117,5461 \\
\hline
\end{tabular}

Nota. Legenda: DPA: dividendos distribuídos por ação - TAM: Logaritmo Natural do Ativo Total - ALAV: Alavancagem, medida pelo Passivo Total dividido pelo Patrimônio Líquido - ROA: Rentabilidade, retorno sobre os ativos, medido pelo Resultado Operacional dividido pelo Ativo Total - DPAEA: Montante que as empresas distribuíram aos acionistas sobre a forma de dividendos no exercício anterior (em R\$) - Q: Q de Tobin - BETA: Risco sistemático - MTB: Market-to-book, medido pelo Valor de mercado ajustado dividido pelo valor contábil da firma (PL) - CRESC: Crescimento dos lucros medido pela diferença entre o Lucro Atual e o Lucro do Ano Anterior, dividido pelo Lucro do Ano Anterior.

Destaca-se que a média da variável dependente DPA corresponde a aproximadamente 0,92. Ou seja, em média as empresas distribuem cerca de $\mathrm{R} \$ 0,92$ do lucro líquido em forma de dividendos para cada ação aos acionistas no mercado. A amostra é composta por 1001 observações, sendo que a frequência da variável GC corresponde a 883 observações (cerca de $88 \%$ do total) para o grupo de firmas pertencentes ao Mercado Tradicional e Nível 1 e 118 observações (cerca de 12\% do total) de firmas que compõem o conjunto do Nível 2 e Novo Mercado da BM\&F Bovespa.

Na Tabela 2 apresenta-se a matriz de correlação das variáveis da pesquisa:

Tabela 2: Correlação entre as variáveis

\begin{tabular}{|c|c|c|c|c|c|c|c|c|c|c|}
\hline & DPA & TAM & ALAV & ROA & DPAEA & Q & MTB & BETA & CRESC & GC \\
\hline DPA & 1,0000 & & & & & & & & & \\
\hline TAM & $0,4315^{*}$ & 1,0000 & & & & & & & & \\
\hline ALAV & 0,0377 & $0,2840^{*}$ & 1,0000 & & & & & & & \\
\hline ROA & $0,3321^{*}$ & $0,2688^{*}$ & $-0,0121$ & 1,0000 & & & & & & \\
\hline DPAEA & $0,9980^{*}$ & $0,4380^{*}$ & 0,0424 & $0,3456^{*}$ & 1,0000 & & & & & \\
\hline Q & $-0,0401$ & $-0,2141^{*}$ & $-0,3690^{*}$ & $0,2003^{*}$ & $-0,0366$ & 1,0000 & & & & \\
\hline MTB & $0,2277^{*}$ & $0,2464^{*}$ & $0,4405^{*}$ & $0,4119^{*}$ & $0,2290^{*}$ & $0,2290^{*}$ & 1,0000 & & & \\
\hline BETA & $-0,0957^{*}$ & $0,2234^{*}$ & $0,0679^{*}$ & $-0,0797^{*}$ & $-0,0995^{*}$ & $-0,0605$ & $-0,0117$ & 1,0000 & & \\
\hline CRESC & $0,0781^{*}$ & 0,0249 & $-0,0898^{*}$ & $0,1890^{*}$ & $0,0756^{*}$ & $0,0928^{*}$ & $0,0931^{*}$ & $-0,0548$ & 1,0000 & \\
\hline GC & 0,0068 & $0,0788^{*}$ & $0,0699^{*}$ & 0,0510 & 0,0172 & 0,0479 & $0,1906^{*}$ & 0,0008 & 0,0366 & 1,0000 \\
\hline
\end{tabular}

Nota. Legenda: DPA: dividendos distribuídos por ação - TAM: Logaritmo Natural do Ativo Total - ALAV: Alavancagem, medida pelo Passivo Total dividido pelo Patrimônio Líquido - ROA: Rentabilidade, retorno sobre os ativos, medido pelo Resultado Operacional dividido pelo Ativo Total - DPAEA: Montante que as empresas distribuíram aos acionistas sobre a forma de dividendos no exercício anterior (em R\$) - Q: Q de Tobin - BETA: Risco sistemático - MTB: Market-to-book, medido pelo Valor de mercado ajustado dividido pelo valor contábil da firma (PL) - CRESC: Crescimento dos lucros, medido pela diferença entre o Lucro Atual e o Lucro do Ano Anterior, dividido pelo Lucro do Ano Anterior 
Pela análise da Tabela 2, verificou-se que apenas a variável independente DPAEA apresentou alta correlação com a variável dependente. Com relação à variável dependente, algumas apresentam alta correlação significante positiva entre si, como pode ser observado com as marcações em asterisco (*). Entretanto, analisou-se se tais correlações impactavam os resultados em termos de multicolinearidade e, através do teste VIF (Variance Inflation Fator), verificou-se a ausência deste problema no modelo.

Os resultados da tabela de correlações não apontam no sentido de corroborar a hipótese $\mathrm{H} 1$ desta pesquisa em que se sugere haver uma relação positiva entre GC e distribuição de dividendos, já que a correlação entre essas variáveis de interesse não foi significativa. Dessa forma, a análise da regressão a partir do modelo proposto com as variáveis de controle faz-se mister para inferir se existe tal relação.

Ressalta-se que todos os coeficientes das regressões estimadas foram obtidos por meio de modelo Pooled-OLS. Esse método foi adotado porque ao aplicar o teste de efeitos específicos, e o teste de Breusch-Pagan, concluiu-se que não há heterogeneidade nas unidades cross section desse estudo e, portanto, utilizou-se a regressão Pooled-OLS. O teste de Baum identificou que existe heterocedasticidade na variância do termo de erro. Além disso, os resultados obtidos no teste de Wooldridge apontaram também para a existência do problema da autocorrelação. Através do comando robust do software Stata ${ }^{\oplus} 11$, foram corrigidos esses problemas.

Na análise da Tabela 3, com ênfase na variável independente de teste GC, pode-se dizer que ela é significante e positiva ao nível de $5 \%$ na mensuração do volume de dividendos distribuídos pelas empresas e que, o fato da firma pertencer aos níveis diferenciados de GC da Bovespa N2 (Nível 2) e NM (Novo Mercado), proporciona uma maior distribuição de dividendos, corroborando com $\mathrm{H} 1$, a qual presume que existe relação positiva entre a GC de empresas e a distribuição de dividendos aos acionistas das companhias listadas na BM\&F Bovespa. Reforça-se, assim, a influência da Teoria de Agência e da Teoria do Passáro na Mão, na medida em que as empresas bem governadas se alinham às expectativas de remuneração de seus acionistas (aumentando o pagamento de dividendos). Dessa forma, infere-se no presente estudo que empresas com melhores práticas de governança corporativa pagam dividendos maiores do que aquelas com práticas de governança incipientes, confirmando trabalhos como Jiraporn, Kim e Kim (2011), Kowalewski, Stetsyuk e Talavera (2007) e Zagonel (2013). Por outro lado, este achado contraria os resultados de Bachmann, Azevedo e Clemente (2012) e Dutta e Chang (2012) que encontraram relação negativa significativa entre GC e distribuição de dividendos.

Como pode ser observado na tabela 3, há relação significante positiva entre as variáveis DPA e MTB. O resultado relativo à variável MTB corrobora com a pesquisa de Forti, Peixoto e Alves (2015), e Lintner (1956) que justificam tal comportamento apontando que o mercado paga um prêmio por empresas que distribuem mais lucros na forma de dividendos aos seus acionistas.

Adicionalmente, foi verificada uma significância positiva na variável DPAEA ao nível de 1\%. Portanto, o valor que a empresa paga de dividendos aos seus acionistas em determinado exercício varia positivamente com o montante distribuído no exercício imediatamente anterior. A respeito da variável DPAEA, verifica-se aderência a todos os estudos de base (Lintner, 1956; Arrazola, Hevia \& Mato,1992; Bagüés \& Fumás, 1995; Escuer \& Cabestre, 1995; Benzinho, 2007; Sanchéz, 2007) quanto ao efeito da variável, com relação significante positiva. Quanto a este resultado específico, verifica-se que há alinhamento com o esperado até então, em virtude do contexto específico brasileiro, sobretudo pelo histórico que a prática de distribuição de dividendos tem no mercado de capitais. Conforme mencionado anteriormente, este fato inclusive é um dos motivadores e diferenciais desta pesquisa. 
A introdução da variável SETOR como variável de controle mostrou que é possível inferir que existem empresas de setores da economia que distribuem mais seus lucros na forma de dividendos. Os setores 13 (Siderurgia e Metalurgia), 15 (Têxtil) e 2, 9 e 10 (Comércio, Outros e Papel e Celulose) apresentaram resultados com significância estatística nessa pesquisa, todos positivos. Outros estudos sobre dividendos que também utilizaram a variável de controle setorial foram Silveira e Bellato (2006) e Rozeff (1982). Na análise destes resultados, a maior distribuição de dividendos verificada, por exemplo, no setor de siderurgia e metalurgia, reitera a relevância e a notoriedade de empresas destes segmentos na composição do mercado de capitais, tendo como exemplo a Vale e a CSN (Companhia Siderúrgica Nacional) que, por meio do maior motante de dividendos distribuídos aos acionistas, fomentam o investimento no mercado de capitais e confirmam suas posições enquanto expoentes do mesmo. Sobre os setores têxtil e de comércio, é pertinente destacar sua queda de participação na formação do PIB brasileiro no ano de 2014 (dados da Associação Brasileira da Indústria Têxtil e de Confecção e da Confederação Nacional do Comércio) indicando que, para garantir suas formas de financiamento, o cenário adverso no mercado de atuação pode estar sendo compensado pelas empresas com meIhor remuneração aos seus acionistas. Por outro lado, dados da Consufor, consultoria especializada na análise do mercado de celulose, madeira e papel, indicam que este setor se expandiu 13\% em 2014, portanto, abrindo espaço para novos investimentos e gerando demanda para novos investimentos, com possível melhor remuneração.

Cabe considerar ainda que o exercício de 2004 também apresentou significância positiva, de 10\%, o que abre espaço para a discussão de como o período pode ser relevante no comportamento das companhias quanto à remuneração de seus acionistas. Embora não seja esse o foco da presente pesquisa, partindo da Teoria do Pássaro na Mão, um ano como o de 2004 ter se apresentado como significante, remete à tendência de que as empresas procuram se manter atrativas através de maiores e/ou mais frequentes dividendos. Surge aqui uma oportunidade para pesquisas futuras.

Em relação às demais variáveis, embora elas tenham apresentado relação positiva com o montante de dividendos distribuídos pelas empresas da BM\&F Bovespa, como o esperado, não se apresentaram significantes. Os resultados para o ano de 2013 foram omitidos por apresentarem colinearidade.

Tabela 3: Resultados do Modelo de Regressão, que associa Dividendos por Ação e Governança Corporativa.

\begin{tabular}{|c|c|c|c|c|}
\hline DPA & Coeficiente & Desvio padrão & $\mathrm{t}$ & $\mathrm{P}>|\mathrm{t}|$ \\
\hline TAM & 0,0008 & 0,0011 & 0,77 & 0,443 \\
\hline ALAV & $-0,0007$ & 0,0005 & $-1,42$ & 0,157 \\
\hline ROA & 0,0109 & 0,0133 & 0,82 & 0,413 \\
\hline DPAEA & 0,9740 & 0,0036 & 270,09 & $0,000^{* * *}$ \\
\hline Q & $-0,0004$ & 0,0012 & $-0,36$ & 0,722 \\
\hline MTB & 0,0017 & 0,0006 & 2,73 & $0,006^{* * *}$ \\
\hline BETA & $-0,0006$ & 0,0016 & $-0,37$ & 0,712 \\
\hline CRES & 0,0008 & 0,0007 & 1,03 & 0,306 \\
\hline CRASH & 0,0043 & 0,0043 & 1,02 & 0,310 \\
\hline GC & 0,0051 & 0,0024 & 2,16 & $0,031^{* *}$ \\
\hline SETOR & & & & \\
\hline Comércio & 0,0069055 & 0,003753 & 1,84 & $0,066^{*}$ \\
\hline Construção & 0,0062817 & 0,0045542 & 1,38 & 0,168 \\
\hline Eletroeletrônicos & 0,0016465 & 0,0026899 & 0,61 & 0,541 \\
\hline Energia Elétrica & 0,0002913 & 0,0037973 & 0,08 & 0,939 \\
\hline Mineraçăo & 0,0077489 & 0,0049979 & 1,55 & 0,122 \\
\hline & & & & \\
\hline
\end{tabular}




\begin{tabular}{|c|c|c|c|c|}
\hline Máquinas Indust & $-0,0019028$ & 0,0061758 & $-0,31$ & 0,758 \\
\hline Outros & 0,0046895 & 0,0026202 & 1,79 & $0,074^{*}$ \\
\hline Papel e Celulose & 0,0080741 & 0,0041424 & 1,95 & $0,052^{*}$ \\
\hline Petróleo e Gas & $-0,0097718$ & 0,0435755 & $-0,22$ & 0,823 \\
\hline Química & 0,0038956 & 0,0028364 & 1,37 & 0,170 \\
\hline Siderur \& Metalur & 0,0079889 & 0,0030086 & 2,66 & $0,008^{* * *}$ \\
\hline Telecomunicações & $-0,0006011$ & 0,0032138 & $-0,19$ & 0,852 \\
\hline Textil & 0,0061966 & 0,0030322 & 2,04 & $0,041^{* *}$ \\
\hline Transporte Serviç & $-0,0019242$ & 0,0037721 & $-0,51$ & 0,610 \\
\hline Veiculos e peças & 0,0007935 & 0,0024302 & 0,33 & 0,744 \\
\hline \multicolumn{5}{|l|}{ ANO } \\
\hline 2003 & 0,0100933 & 0,0061537 & 1,64 & 0,101 \\
\hline 2004 & 0,0075816 & 0,0043309 & 1,75 & $0,080^{*}$ \\
\hline 2005 & $-0,00102$ & 0,0062457 & $-0,16$ & 0,870 \\
\hline 2006 & 0,0148902 & 0,0108707 & 1,37 & 0,171 \\
\hline 2007 & 0,0021837 & 0,0035039 & 0,62 & 0,533 \\
\hline 2008 & 0,0038298 & 0,0034436 & 1,11 & 0,266 \\
\hline 2009 & $-0,0021636$ & 0,0026188 & $-0,83$ & 0,409 \\
\hline 2010 & 0,0037751 & 0,0033029 & 1,14 & 0,253 \\
\hline 2011 & 0,0025829 & 0,0034327 & 0,75 & 0,452 \\
\hline 2012 & $-0,0009609$ & 0,0044807 & $-0,21$ & 0,830 \\
\hline 2013 & Ommited & & & \\
\hline Constante & $-0,0180641$ & 0,0150016 & $-1,20$ & 0,229 \\
\hline
\end{tabular}

Efeitos específicos: Prob $>\mathrm{F}>0,05$

Breusch-Pagan: Prob $>$ chi2 $=1,00>0,05$

Heterocedasticidade de Baum: Prob $>$ chi2 $=0,00$

Autocorrelação de Wooldridge: Prob $>F=0,00<0,05)$

Nota. Legenda: * apresenta os coeficientes de correlação estatisticamente significantes ao nível de $10 \%$ - ** apresenta os coeficientes de correlação estatisticamente significantes ao nível de $5 \%$ - *** apresenta os coeficientes de correlação estatisticamente significantes ao nível de 1\% - DPA: dividen dos distribuídos por ação - TAM: Logaritmo Natural do Ativo Total - ALAV: Alavancagem, medida pelo Passivo Total dividido pelo Patrimônio Líquido - ROA: Rentabilidade, retorno sobre os ativos, medido pelo Resultado Operacional dividido pelo Ativo Total - DPAEA: Montante que as empresas distribui ram aos acionistas sobre a forma de dividendos no exercício anterior (em R\$) - Q: $\mathrm{Q}$ de Tobin - BETA: Risco sistemático - MTB: Market-to-book, medido pelo Valor de mercado ajustado dividido pelo valor contábil da firma (PL) - CRESC: Crescimento dos lucros, medido pela diferença entre o Lucro Atual com Lucro Ano Anterior, dividido pelo Lucro Ano Anterior.

Fonte: Resultados da pesquisa

Os resultados apontam que empresas que compõem os níveis mais altos de GC possuem maior transparência informacional, distribuindo maior volume de dividendos advindos dos lucros auferidos, de forma a recompensar seus acionistas. 


\section{CONSIDERAÇÕES FINAIS}

Esta pesquisa teve como objetivo avaliar uma possível relação entre a qualidade da governança corporativa e a distribuição de dividendos considerando a realidade das empresas brasileiras listadas na BM\&FBovespa, no período de 2002 a 2013. Quanto ao método utilizado, após os testes de diagnóstico dos modelos econométricos, optou-se pela abordagem Pooled-OLS.

Os resultados apontaram para uma relação significante e positiva entre distribuição de dividendos e GC. As variáveis de controle DPAEA (montante de dividendos que as empresas distribuíram aos acionistas no ano anterior) e MTB (razão valor de mercado/valor contábil das ações da empresa) também se mostraram significantes, ambas com relação positiva, corroborando os estudos de Lintner (1956), Arrazola, Hevia e Mato (1992), Bagüés e Fumás (1995), Escuer e Cabestre (1995), Benzinho (2007), Sanchéz (2007) e Forti, Peixoto e Alves (2015).

Dessa forma, os dados apontam que ativos pertencentes a níveis mais altos de GC da BM\&F Bovespa (Nível 2 e Novo Mercado) distribuem um maior montante de dividendos a seus acionistas, em detrimento de firmas pertencentes a níveis mais baixos de GC (Nível 1 e Mercado Tradicional) segundo o critério da BM\&F Bovespa de classificação. Portanto, houve a aceitação de $\mathrm{H} 1$ que diz existir relação positiva entre a GC das empresas e a distribuição de dividendos aos acionistas das companhias listadas na BM\&F Bovespa, estando de acordo com Teoria do Pássaro na Mão e com o trabalho de Jiraporn, Kim e Kim (2011), e contrariando o estudo de Forti, Peixoto e Alves (2015).

Outro resultado apontado é que o ano pode ser uma variável significante quando se analisa o montante distribuído sob a forma de dividendos. Apesar da variável CRASH (referente aos anos de 2002, 2006 e 2008) não ter apresentado significância estatística e não ter confirmado o esperado na presente pesquisa, o ano de 2004 apresentou significância positiva ao nível de 10\%, indicando que em tal ano houve maior distribuição de dividendos, o que é coerente com o momento de crescimento econômico e aberturas de capital que o Brasil vinha passando.

Uma limitação da pesquisa consiste na expansão dos dados, sobretudo de GC, visto que a base da BM\&F Bovespa apresenta restrições de dados quanto à evolução anual de cada empresa em termos de níveis de GC (Mercado Tradicional, Nível 1, Nível 2 e Novo Mercado), bem como o fato de terem sido considerados tanto os juros sobre o capital próprio, quanto os dividendos, mitigada, entretanto, pela configuração do cenário tributário das empresas brasileiras de capital aberto, em que a distribuição via juros sobre capital próprio também pode ser relevante na explicação dos efeitos da GC na distribuição de resultados.

Essa pesquisa contribuiu para a teoria de dividendos e de governança corporativa no sentido em que se pôde inferir que os acionistas que escolhem ativos pertencentes a níveis mais altos de GC da BM\&F Bovespa (Nível 2 e Novo Mercado) em detrimento de ativos pertencentes ao Nível 1 e Mercado Tradicional da referida bolsa distribuem maior riqueza na forma de dividendos. Além disso, percebeu-se que períodos de crise não afetam significativamente a distribuição de lucros por meio de dividendos por parte das empresas. Algumas sugestões para trabalhos futuros envolvem a análise dos quatro níveis de GC em separado, o uso de outras proxies para governança e o uso de métodos econométricos distintos para avaliar as variáveis de interesse. 


\section{REFERÊNCIAS}

Aivazian, V., Booth, I. \& Cleary, S. (2003). Do Emerging Market Firms Follow Different Dividend Policies From US Firms? Journal of Financial Research, 26(3): 371-387.

Almeida, M. A., Santos, J. F. dos. (2008). O Efeito das Dimensões de Governança Corporativa sobre o Payout das Empresas Não Financeiras Brasileiras. In: XXXII ENANPAD - Encontro da ANPAD, 2008, Rio de Janeiro: Associação Nacional de Pós-Graduação e Pesquisa em Administração.

Arrazola M., Hevia, J. \& Mato, G. (1992). Determinantes de La distribución de dividendos. Investigaciones Economicas, 16(2): 235-258. Disponível em: <http://www.fundacionsepi.es/revistas/paperArchive/ May1992/v16i2a4.pdf>. Acesso em 08.mai.2014.

Bachmann, R. K. B., Azevedo, S. U. de, Clemente, A. (2012). Regularidade no pagamento de dividendos e governança corporativa: estudo em companhias de capital aberto listadas na BM\&F Bovespa. Revista de Gestão, Finanças e Contabilidade, 2(2): 68-79.

Bagüés, E. \& Fumás, V. (1995). Explicaciones alternativas para la politica de dividendos: analisis empírico com datos empresariales españoles. InvestigacionesEconomicas, 19(3): 329-348. Disponível em: <http://www.fundacionsepi.es/revistas/paperArchive/Sep1995/v19i3a1.pdf>. Acesso em: 08.mai.2014.

Bellato, L. L. N, Silveira, A. D. M \& Savoia, J. R. F. (2006). Influência da estrutura de propriedade sobre a taxa de pagamento de dividendos das companhias abertas brasileiras. In: Encontro Nacional Da Associação Nacional Dos Programas De Pós-Graduação Em Administração, 30, Salvador. Anais eletrônicos: Salvador: ANPAD. Disponível em: <http://www.anpad.org.br/enanpad/2006/dwn/enanpad2006-ficd-2274.pdf>. Acesso em 19.set.2014.

Benzinho, J. (2007). The dividend policy of the Portuguese corporations: evidence from Euronext Lisbon. MPRA Papper, (1137): 13. Disponível em: <http://mpra.ub.uni-muenchen.de/1137/1/MPRA_paper_1137. pdf $>$. Acesso em: 08.mai.2014.

BM\&FBOVESPA. Disponível em: <www.bmfbovespa.com.br>. Acesso em 25/08/2014.

Bruni, A. L., Famá, R., Firmino, A. \& Gama, A. (2003). O anúncio da distribuição de dividendos e seu efeito sobre os preços das ações: um estudo empírico no Brasil. In: III Congresso USP de Controladoria e Contabilidade (Faculdade de Economia, Administração e Contabilidade da Universidade de São Paulo), São Paulo. Anais...São Paulo: USP, 1-20.

Carvalhal da Silva, A. L. (2004). Governança Corporativa, Valor, Alavancagem e Política de Dividendos das Empresas Brasileiras. Revista de Administração da Universidade de São Paulo. São Paulo, 39(4): 348-361.

Claessens, S., Djankov, S., Fan, J. P. H. \& Lang, L. H. P. (2002). Disentangling the Incentive and Entrenchment Effects of Large Shareholdings. The Journal of Finance, 57(6): 2741-2771. 
Comissão de Valores Mobiliários (2002). Recomendações da CVM Sobre Governança Corporativa. Rio de Janeiro. Disponível em: < www.cvm.gov.br/port/public/publ/cartilha/cartilha.doc>. Acesso em: 01.07.2014.

Decourt, R. F. \& Procianoy, J. L. (2012). O Processo Decisório sobre a Distribuição de Lucros das Empresas Listadas na BM \& FBOVESPA: Survey com CFOs. Revista Brasileira de Finanças, 10: 461-498, outubro-dezembro. Disponível em:< http://www.redalyc.org/pdf/3058/305826565002.pdf>. Acesso em:21.09.2014.

Dutta, S. \& Chang, B. (2012). Dividends and Corporate Governance: Canadian Evidence. The IUP Journal of Applied Finance, 18(4): 5-30. Disponível em: http://ssrn.com/abstract=2184699. Acesso em 02 out. 2014.

Escuer, M. \& Cabestre, F. (1995). El valor informativo de los dividendos sobre los beneficios futuros em el mercado de capitales español. Revista Española de Financiación y Contabilidad, 24(82): 201-220. Disponível em: <http://www.aeca.es/pub/refc/articulos.php?id=0406>. Acesso em: 08.mai.2014.

Fatemi, A. \& Bildik, R. (2012). Yes, dividends are disappearing: worldwide evidence. Journal of Banking \& Finance, 36(1): 662-677.

Forti, C. A. B., Peixoto, F. M. e Alves, D. L. (2015). Determinant Factors of Dividend Payments in Brazil. Revista Contabilidade \& Finanças, 26(68): 167-180.

Forti, C. A. B., Schiozer, R. F. (2015). Bank dividends and signaling to information-sensitive depositors. Journal of Banking \& Finance, 56: 1-11.

Gama, U. de O., Barbosa, M. V., Coutinho, R. E.T., Ferreira, S. \& Novikoff, C. (2013). Governança Corporativa: Valor de Mercado das Ações no Brasil e o Novo Mercado. In: Simpósio de Excelência em Gestão e Tecnologia, [S.I.]. Anais Eletrônicos... X SEGET. Disponível em:<http://www.aedb.br/seget/artigos13/6218612. pdf $>$. Acessoem: 29 abr. 2014.

Gill, A. S. \& Obradovich, J. D. (2012). Corporate Governance, Institutional Ownership, and the Decision to pay the Amount of Dividends: Evidence from USA. International Research Journal of Finance \& Economics, 97: 60.

Gordon, M. J. (1959). Dividends, earnings, and stock prices.The Review of Economics and Statistics, 41(2): 99-105. Disponívelem: <https://www.wiso.uni-hamburg.de/fileadmin/sozialoekonomie/bwl/bassen/ Lehre/International_Finance_I/Assignments/1959_Gordon.pdf>. Acessoem: 19.set.2014

Gordon, Myron J. (1963). Optimal Investment and Financing Policy. The Journal of Finance, 18(2): 264272, May.

Gorga, E. (2004). A cultura brasileira como fator determinante na governança corporativa e no desenvolvimento do mercado de capitais. R. Adm., 39(4): 309-326, out./nov./dez. 
Guimarães, T. M., Marques, T. A. e Peixoto, F. M. (2014). A concentração acionária no Brasil: análise dos impactos no desempenho, valor e risco das empresas. In: $14^{\circ}$ Encontro Brasileiro de Finanças (14 EBFin), Recife-PE, Sociedade Brasileira de Finanças.

Jensen, M. C. (1986). Agency costs of free cash flow, corporate finance and takeovers. American Economics Review, 76: 323-339.

Jensen, M, Meckling, W. (1976). Theory of the firm: managerial behavior, agency costs and ownership structure. Journal of Financial Economics, 3(4): 305-360.

Jiraporn, P., Kim, J., \& Kim, S. Y. (2011). Dividend payouts and corporate governance quality: an empirical investigation. The Financial Review, 46: 251-279.

John, K \& Knyazeva, A. (2006). Payout policy, agency conflicts and corporate governance. Working paper, New York University.

Kania, S. L. \& Bacon, F. W. (2005). What factors motivate the corporate dividend decision. ASBBS E-Journal, 1(1): 97-107.

Kowalewski, O., Stetsyuk, I. \& Talavera, O. (2007). Corporate Governance and dividend policy in Poland. Working Paper. Disponível em: http://papers.ssrn.com/sol3/papers.cfm?abstract_id=986111. Acesso em 02 out. 2014.

La Porta, R., Lopez-de-Silanes, F. \& Shleifer, A. \& Vishny, R. (2000). Agency Problems and Dividend Policies around the World. The Journal of Finance, 55(1): 1-33.

La Porta, R., Shleifer, A., Lopez-de-Silanes, F. \& Vishny, R. (2002). Investor protection and corporate valuation. Journal of Finance, 57(3):1147-1170.

Lintner, J. (1956). Distribution of incomes of corporations among dividends, retained and taxes.The American Economic Review, 46(2): 97-113. Disponível em: <http://ecsocman.hse.ru/data/890/126/1231/ lintner_1956.pdf>. Acesso em: 21.set.2014.

Martins, A. I. \& Famá, R. (2012). O que revelam os estudos realizados no Brasil sobre política de dividendos? Revista de Administração de Empresas, 52(1): 24-59.

Mather, P. \& Peirson, G. (2006). Financial covenants in the markets for public and private debt. Accounting and Finance, 46(2): 285-307. Disponível em: < http://onlinelibrary.wiley.com/doi/10.1111/j. 1467-629X.2006.00168.x/pdf>. Acesso em 14.out.2014.

Mehar, A. (2005). Corporate Governance and dividend policy. Pakistan Economic and Social Review, 43(1): 115-128.

Michaely, R. \& Roberts, M. (2006). Dividend smoothing, agency costs, and information asymmetry: Lessons from the dividend policies of private firms. Working paper, Cornell University. 
Modigliani, Franco \& Miller, Merton. (1961). Dividend Policy, Growth and the Valuation of Shares. Journal of Business, 34(4): 411-433, Oct.

Moh'D, M. A., Perry, L. G. \& Rimbey, J. N. (1995). An investigation of the dynamic relationship between agency theory and dividend policy. The financial Review, 30(2): 367-385.

Moreiras, L. M. F., Tambosi Filho, E. \& Garcia, F. G. (2009). Dividendos, Informação Assimétrica e Conflito de Agência: Comparação entre o Novo e o Mercado Tradicional. Pensamento e Realidade, 24(2): 2009.

Myers, S. C. \& Majluf, N. S. (1984). Corporate Financing and Investments decisions when firms have information that investors do not have. Journal of Financial Economics, 3: 187-221.

Novis Neto, J. A. (2002). Dividend Yield e Persistência de Retornos Anormais nas ações: evidência do mercado brasileiro. 66 f. Dissertação (Mestrado em Administração de Empresas) - EAESP/FGV, São Paulo, SP. Disponível em: <http://bibliotecadigital.fgv.br/dspace/bitstream/handle/10438/4984/1200201661. pdf?sequence $=1>$. Acesso em: 21.jul.2014

O'Connor, T. (2012). Dividend payout and corporate governance along the corporate life-cycle. Working Paper. Disponível em: http://economics.nuim.ie/sites/economics.nuim.ie/files/working-papers/N22812.pdf. Acesso em 02 out. 2014.

Peixoto, F. M. \& Buccini, A. R. A. (2014). Separação entre propriedade e controle e sua relação com desempenho e valor de empresas brasileiras: onde estamos? Revista de Contabilidade e Organizações, 7(18).

Peixoto, F. M., Amaral, H. F., Correia, L.F. \& Neves, J. C. C. (2014). Governança Corporativa e crises: mecanismos importantes durante ciclos econômicos distintos. Revista de Ciências da Administração, 16(39):, 119-133.

Presidência da República. Casa Civil. Subchefia para Assuntos Jurídicos. Lei no 6.404, de 15 de dezembro de 1976. Dispõe sobre as Sociedades por Ações. Dez. 1976.

Procianoy, J. L. (1996). Dividendos e tributação: o que aconteceu após 1988-1989. RAUSP-Revista de Administração, 31(2): 7-18.

Renneboog, L. \& Szilagyi, P. (2006). How relevant is dividend policy under low shareholder protection? Working paper, Tilburg University.

Renneboog, L. \& Trojanowski, G. (2011). Patterns in payout policy and payout channel choice. Journal of Banking \& Finance, 35(6): 1477-1490.

Ribeiro, M. A., Filho, J. M. D., Carvalho Júnior, C. V. de O., Almeida, C. S. L. \& Santos, E. B. dos. (2013).Um Estudo sobre a Associação entre Práticas de Governança Corporativa e Políticas de Dividendos no Brasil. In:X SEGet - Simpósio de Excelência em Gestão e Tecnologia, Resende: Universidade Católica de Brasília.

Rozeff, M. (1982). Growth, beta, and agency costs as determinants of dividend payout ratios, Journal of Financial Research, 5: 249-259.

Sanchéz, M. (2007). Objectivos de la política de dividendos em las empresas Del IBEX-35. Análisis financeiro, 104: 54-61.

Sawicki, J. (2009). Corporate governance and dividend policy in southeast Asia pre - and post-crisis. The European Journal of Finance, 15(2): 211-230.

Shleifer, A. \& Vishny, R.W. (1997). A survey of corporate governance. Journal of Finance, Berkeley, 52: 737-783, jun. 
Silva, A. L. C. (2004). Governança corporativa, valor, alavancagem e política de dividendos das empresas brasileiras. RAUSP - Revista de Administração, 39(4): 348-361.

Silva, A. L. C. \& CHIEN, A. C. (2013). Remuneração executiva, valor e desempenho das empresas brasileiras listadas. Revista Brasileira de Finanças, 11(4): 481-502.

Silva, S. M. B. (2003). The influence of agency costs on the dividend policy of Brazilian listed companies. In: Encontro Nacional Da Associação Nacional Dos Programas De Pós-Graduação Em Administração, 27, Atibaia. Anais. Atibaia: ANPAD. Disponível em: <http://www.anpad.org.br/diversos/trabalhos/ EnANPAD/enanpad_2003/FIN/2003_FIN2.pdf>. Acesso em 08.mai.2014.

Silveira, A. D. M., Bellato, L. L. N. (2006). Influência da Estrutura de Propriedade sobre a Política de Dividendos das Companhias Abertas Brasileiras. In: VI Encontro Brasileiro de Finanças, Vitória. Anais. Vitória: EBFin.

Sonza, I. B. \& Kloeckner, G. O. (2014). Governança em estruturas proprietárias concentradas: novas evidências para o Brasil. RAUSP - Revista de Administração da USP, 49(2): 322-338.

Vidal, T. L. (2011). Crises financeiras: efeito contágio ou interdependência entre os países? Evidências utilizando uma abordagem multivariada. Dissertação (Mestrado) - Universidade de São Paulo, São Paulo.

Zagonel, T. (2013). Política de Dividendos, Tributação e Governança Corporativa no Brasil. 83 f. Dissertação (Mestrado em Administração) - Universidade Federal do Rio Grande do Sul, Porto Alegre. 